\title{
Monitoring temporal patterns of vertical hyporheic flux via distributed temperature sensors
}

\author{
XIAORU SU' ${ }^{1}$, LONGCANG SHU ${ }^{1}$, WEI LI ${ }^{2}$, CHENGPENG LU ${ }^{1}$, JINGSI ZHU ${ }^{1}$, \\ GUANGDONG WU ${ }^{1}$, XI WANG ${ }^{1}$ \& GUAN WANG ${ }^{1}$ \\ 1 College of Hydrology and Water Resources, Hohai University, Nanjing, 210098, China \\ luchengpeng@hhu.edu.cn \\ 2 Geological Survey of Jiangsu Province, Nanjing, 210098, China
}

\begin{abstract}
Hyporheic exchange is of great significance for evaluating and developing water resources, as well as protecting ecosystem health. Temperature monitoring is one of the powerful tools for recognizing the hyporheic flux with high precision, low cost and great convenience. The streambed temperature at different depths $(0$ to $1.00 \mathrm{~m})$, and the air and stream water temperatures at Dawen River, Jining City, were monitored using distributed temperature sensors (DTS). The temperature series were used to estimate the hyporheic flux through the analytical solution of the governing one-dimensional heat transport equation. The temporal patterns of flux along the vertical profile were analysed. The results indicated that surface water and air temperatures fluctuated approximately sinusoidally, and the groundwater temperature was relatively stable over time. The hyporheic flux at different depths showed different temporal patterns. Moreover, the dynamic curves of hyporheic flux were depth-dependent and probably controlled by the stream water level and groundwater field.
\end{abstract}

Key words temporal pattern; temperature monitoring; hyporheic flux; hyporheic zone; heat transport

\section{INTRODUCTION}

Many researchers have focused on the hyporheic exchange (Rosenberry et al. 2013; Wang et al. 2004), which means the exchange between groundwater and surface water in hyporheic zone. Understanding and quantifying the physical processes and ecological implications of hyporheic exchange is becoming an important subject in hydrogeological and river ecological studies (Schmidt et al. 2006). The hyporheic flux is the carrier of hyporheic exchange, it is defined as the water amount exchanged between groundwater and stream water in the hyporheic zone. The temperatures of the river and streambed can be measured easily and rapidly using robust, inexpensive waterproof temperature sensors. Temperature as a tracer was widely used in analysing recharge and discharge rates, the effects of surface warming, interchange with surface water, the hydraulic conductivity of streambed sediments and basin-scale permeability (Anderson, 2005). In this study we show that the temperature method had the capability to characterize the spatial and temporal heterogeneity of hyporheic flux inexpensively and conveniently.

Estimating hyporheic flux using temperature data have been investigated by some studies. Zhu et al.(2013) estimated the hyporheic flux and surface water temperature via a curve fitting method based on the analytical solution of the one-dimensional steady-state heat transport governing equation by using the temperature data of three river cross-sections in Dawen River, Shandong Province. Significant improvements in data-acquisition and computational techniques enable the use of temperature time series for numerical and analytical estimation of instantaneous hyporheic flux (Constantz and Stonestrom 2003). Hatch et al. (2006) developed a semi-automated computer program for deriving amplitude and phase information from graphically displayed temperature data, and then calculated time varying values of vertical hyporheic flux in an iterative procedure using the amplitude or phase of the selected temperature oscillation, as well as physical properties of the system, including thermal dispersivity.

Researchers have studied the spatial and temporal variability of hyporheic fluxes at a channel scale. Rosenberry et al. (2013) presented several examples indicating that temporal variability of exchange between groundwater and surface water is much more substantial than previously realized. The spatial distribution of hyporheic flux had been discussed by Mamer and Lowry (2013). However, the accurate and quantitative analysis of the heterogeneity is not sufficient. Temperature as a tracer is one of the significant methods for recognizing the hyporheic flux with 
high precision, low cost and great convenience; however, domestic research on this field is still in its infancy. Zhu et al.(2013) estimated the hyporheic flux by using the quasi-steady temperature, and in this study the streambed temperature series collected at the same stream reaches as used for Zhu's paper were used to calculate the instantaneous hyporheic flux. Temporal variability of the vertical hyporheic flux and its depth-dependent patterns were quantified via statistical analysis.

\section{FIELD WORK}

The field site was located $2 \mathrm{~km}$ below Pipashan Dam in a reach of the Dawen River in Jining, Shandong Province (Fig. 1). The Dawen River is a large tributary of the Yellow River and mainly flows from east to west. The length of Dawen River is $209 \mathrm{~km}$ and it drains an $8633 \mathrm{~km}^{2}$ watershed. Dawen River watershed is in the semi-humid region with annual precipitation of $694.0 \mathrm{~mm}$ and annual average temperature of $12.9^{\circ} \mathrm{C}$. The mean annual evaporation is $1100 \mathrm{~mm}$. The annual stream hydrograph is composed of precipitation in the watershed and base flow. The grain size distributions of 10 samples collected from the field test site were obtained using the sieving method, and the results indicated that the streambed sediments were mainly composed of gravelly sand.

The temperature measurements were carried out from $16: 00 \mathrm{~h}$ on 6 November to $08: 00 \mathrm{~h}$ on 9 November 2012 using a kind of button type temperature recorder (Type DS1922L). The temperature recorder can measure temperature data with a given time interval and transmit the observed date to computers. In total, 20 vertical arrays of temperature measurements were distributed along the field test transect, and the array located at the centre of the channel was analysed in this study. The temperature recorders were fixed on to PVC (polyvinylchlorid) pipe and the pipe was inserted into the streambed to a depth of $1.00 \mathrm{~m}$. Five temperature recorders on the PVC pipe simultaneously measured the streambed temperatures time series at depths of 0.05 , $0.15,0.25,0.55$ and $0.95 \mathrm{~m}$. The streambed temperatures were recorded every 5 minutes at the same time as the surface water and air temperatures were monitored at the test transect. The groundwater temperatures adopt the streambed temperatures at depths of $0.95 \mathrm{~m}$ because it was relatively stable over time. River stage data were provided from Daicun Dam gauging station near the test site.



Fig. 1 Location of the field test at Dawen River, Shandong Province.

\section{METHODS OF HYPORHEIC FLUX ESTIMATION}

With the assumption that hyporheic flux in the streambed is essentially vertical, the governing equation for one-dimensional conductive and advective heat transport is:

$$
\frac{K_{f s}}{\rho c} \nabla^{2} T(z)-\frac{\rho_{f} c_{f}}{\rho c} \nabla \cdot(T(z) q)=\frac{\partial T(z)}{\partial t}
$$

where $T(z)\left[{ }^{\circ} \mathrm{C}\right]$ is the streambed temperature at depth $z ; t$ is time $[\mathrm{s}] ; q$ is the vertical Darcy velocity $[\mathrm{m} / \mathrm{s}]$ or vertical hyporheic flux $\left[\mathrm{L} /\left(\mathrm{m}^{2} \cdot \mathrm{d}\right)\right] ; \rho c$ is the volumetric heat capacity of the solidfluid system and $\rho_{f c_{f}}$ is the volumetric heat capacity of the fluid $\left[\mathrm{J} /\left(\mathrm{m}^{3} \cdot \mathrm{K}\right)\right] ; n$ is the porosity [-]. $K_{f s}$ is the thermal conductivity of the saturated sediment $[\mathrm{J} /(\mathrm{s} \cdot \mathrm{m} \cdot \mathrm{K})]$. 
Sinusoidal temperature oscillations could be observed at the stream surface, and were attenuated with increasing depth until towards zero at some streambed depth (Suzuki 1960). This may be due to the hyporheic flux inhibition of the downwards transmission of temperature oscillations from the surface (Hatch et al. 2006). Methods for estimating vertical hyporheic flux were developed from the amplitude attenuation and phase lag of observed temperature time series between different streambed depths.

Kerry et al. (2007) derived a solution to equation (1) which describes the vertical hyporheic flux in terms of amplitude attenuation and time lag of the temperature signal at two streambed depths, as well as the physical and thermal properties of the system:

$$
\left(\frac{H^{3} D}{4 Z}\right) q^{3}-\left(\frac{5 H^{2} D^{2}}{4 z^{2}}\right) q^{2}+\left(\frac{2 H D^{3}}{z^{3}}\right) q+\left(\frac{\pi \rho c}{K_{f s} \tau}\right)-\frac{D^{4}}{z^{4}}=0
$$

where:

$$
\begin{aligned}
& D=\ln \left(\frac{A_{z, t+\Delta t}}{A_{0, t}}\right) \\
& H=\frac{c_{f} \rho_{f}}{K_{f s}}
\end{aligned}
$$

$z$ is the vertical distance between two streambed depths; $q$ is the average vertical hyporheic flux $\left[\mathrm{L} /\left(\mathrm{m}^{2} \cdot \mathrm{d}\right)\right]$ between the two depths. $A_{z, t+\Delta t}$ and $A_{0, t}$ are, respectively, the amplitudes of oscillations at depth $z$ and time $t+\Delta t$, and at depth 0 and time $t$, where $\Delta t$ is the time lag between oscillations at depths $z$ and 0 . Note that in our analysis the flux $q$ is positive in the downward direction. We set $K_{f s}=2.0 \mathrm{~J} /(\mathrm{s} \cdot \mathrm{m}), \rho_{f} c_{f}=4.2 \times 10^{6} \mathrm{~J} /\left(\mathrm{m}^{3} \cdot \mathrm{K}\right), \rho c=2.0 \times 10^{6} \mathrm{~J} /\left(\mathrm{m}^{3} \cdot \mathrm{K}\right)$, and $\tau=86400 \mathrm{~s}$.

The amplitude and phase information of the pure sinusoidal component of each series can be obtained by applying DHR (dynamic harmonic regression) using the Captain Toolbox, a library of functions to be used within the MATLAB (Young et al. 2004). Amplitude information was used here. Equation (2) could be applied with the shallow amplitude of temperatures oscillation at time $t$, and deep amplitude at time $t+\Delta t$ to calculate averaged vertical hyporheic flux. Solving equation (2) for all matched pairs, gives a time series of vertical hyporheic flux at different depths.

\section{RESULTS AND DISCUSSION}

\subsection{Stream water, groundwater and air temperature}

During the monitoring period, the stream water temperatures showed variations with a minimum value of $11.279^{\circ} \mathrm{C}$ and a maximum of $15.838^{\circ} \mathrm{C}$, the average temperature was $13.331^{\circ} \mathrm{C}$ (Fig. 2). The air temperature varied between 3.775 and $22.475^{\circ} \mathrm{C}$ around the overall average of $10.156^{\circ} \mathrm{C}$. It can be seen from Fig. 2 that both the stream water temperatures and the air temperatures

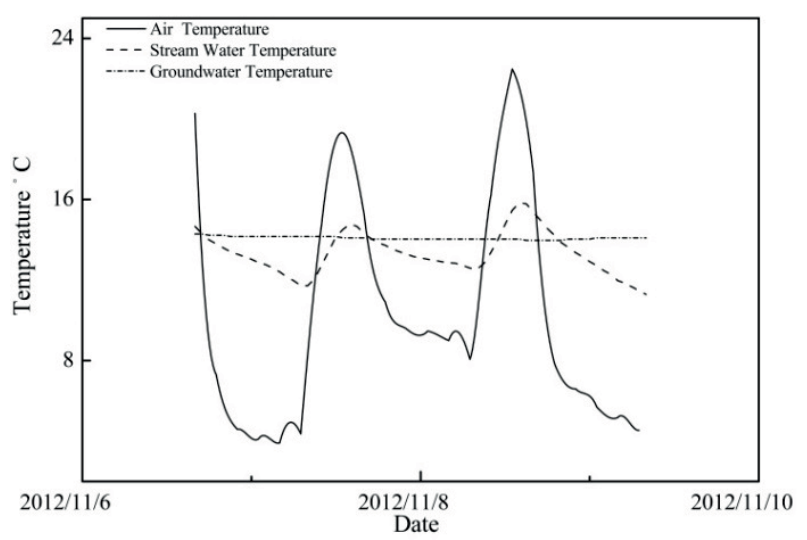

Fig. 2 Stream, groundwater and air temperature during the monitoring period. 
fluctuate approximately sinusoidally. However, the amplitude of the former is significantly damped compared with the latter due to the great difference in heat capacity between stream water and air. The groundwater temperatures varied between 13.973 and $14.286^{\circ} \mathrm{C}$ with an average temperature of $14.089^{\circ} \mathrm{C}$, and showed no significant variation. Figure 2 indicates the groundwater temperatures fluctuate very little and the average temperature of groundwater was higher than that of stream water and air. That is because the surface water temperature was cooler than groundwater temperature in winter.

\subsection{Streambed temperature}

Comparing the temperatures at depths of $0.05,0.15,0.25,0.55$ and $0.95 \mathrm{~m}$ below the streambed during the monitoring period (Fig. 3), it can be seen that the temperatures at depth above $0.95 \mathrm{~m}$ fluctuate approximately sinusoidally with an oscillation period of around $24 \mathrm{~h}$. With the increase of streambed depth, the amplitude attenuation and phase lag of temperature oscillation both increase. At t $0.95 \mathrm{~m}$ depth the temperature fluctuations are strongly damped and become almost non-detectable. DHR was applied to each temperature time series to isolate the temperature sinusoidal oscillations and their amplitude. Temporal vertical hyporheic flux can be calculated with amplitudes at two streambed depths by applying equation (2).

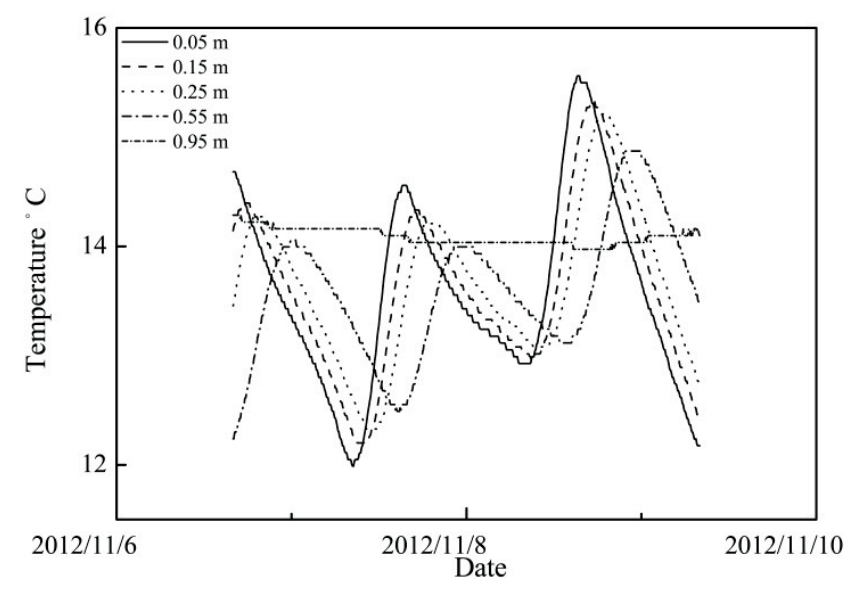

Fig. 3 Temperature time series at various depths below the streambed.

\subsection{Temporal variability of hyporheic flux}

For calculating the vertical hyporheic flux values between each two depths, the changing process of vertical flux at centre-paired depths and stream stage during two days of the monitoring period, from 16:00 h on 6 to 16:00 h on 8 November 2012, are displayed in Fig. 4. Figure 4 (a) shows the patterns of hyporheic flux series at different depths during the monitoring period. The depths of $0.10,0.15,0.30,0.35$ and $0.40 \mathrm{~m}$ show a general trend of decrease at first, then increase at other times, but the same pattern was obscured at the depth of $0.20 \mathrm{~m}$ and the deepest depth had a more complex pattern of flux with two peaks and two valleys. Overall, the dynamic patterns shown at the six shallowest depths were similar to each other and the minimum instantaneous fluxes occur approximately on the night of 7 November. However the minimum flux shows a time lag with increasing depth. Hyporheic flux values are positive in the hyporheic zone, which indicates the fluxes were downwards and the stream water recharged groundwater during the monitoring period.

Hyporheic flux patterns through time are expected to change as the streambed pressure head boundary changes through time due to changing stream discharge and the associated velocity and stage (Mamer and Lowry 2013). The river stage slightly increased during the period of temperature monitoring (Fig. 4 (b)), the fluxes at the two shallowest depths decreased at first then increased in the second half of the period and the flux value at the end of the monitoring period was greater than at the start, demonstrating a consistent relationship with river stage. However the mean fluxes 


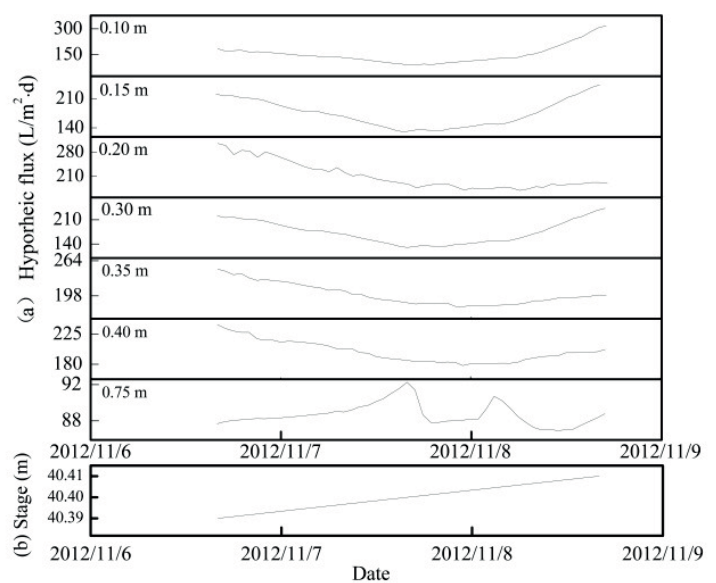

Fig. 4 Dynamic hyporheic flux at centre-paired depths and stream stage changing process during the monitoring period.

at depths of $0.20,0.35$ and $0.40 \mathrm{~m}$ did not increasing over time, suggesting that hyporheic flux is probably affected by the river stage dynamics, but is not solely dependent on it. The groundwater flow distribution and its dynamics probably significantly affected the pattern of hyporheic flux.

\subsection{Depth-dependent hyporheic flux}

For conducting statistical analysis of hyporheic flux at different depths, Box-whisker plots were obtained from calculated flux values, to show the extremes and interquartile range (Fig. 5). The horizontal line indicates the median value.

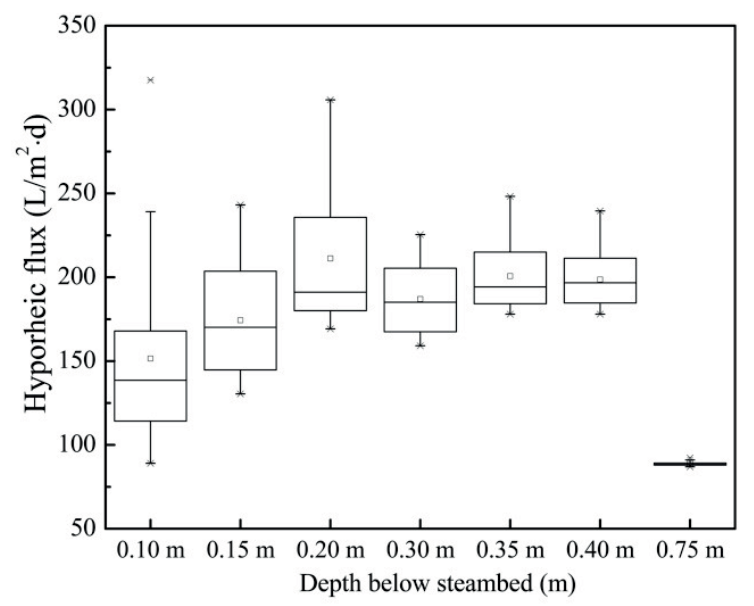

Fig. 5 Box-whisker plot of vertical hyporheic flux at different depth.

The vertical hyporheic flux can vary significantly with depth (Buffington \& Tonina, 2009). In this study, the highest flux of $306 \mathrm{~L} /\left(\mathrm{m}^{2} \cdot \mathrm{d}\right)$ and the lowest flux of $87 \mathrm{~L} /\left(\mathrm{m}^{2} \cdot \mathrm{d}\right)$ were measured at depths of $0.20 \mathrm{~m}$ and $0.75 \mathrm{~m}$, respectively. Overall, the hyporheic exchange in the shallow zone below the streambed was strongest in our study. The highest variation range from $89-239 \mathrm{~L} /\left(\mathrm{m}^{2} \cdot \mathrm{d}\right)$ can be seen at $0.10 \mathrm{~m}$ depth, and overall, the vertical flux in the shallow zone had a higher variation range, meaning more variability, such as the flux at depth of $0.10,0.15$ and $0.20 \mathrm{~m}$. On the other hand, the fluxes below $0.30 \mathrm{~m}$ depth show a relatively lower hyporheic flux variation, especially at $0.75 \mathrm{~m}$ with the smallest variation range from $87-92 \mathrm{~L} /\left(\mathrm{m}^{2} \cdot \mathrm{d}\right)$. It can be concluded that the hyporheic flux values tended to be stable with the increasing of depth. The high variability of flux represented by the box lengths also reveals the strong dynamics of the vertical flux during the monitoring period. As described earlier, the fluxes in the shallow part of the hyporheic zone 
showed a general trend of decrease at first then increase later, and the deepest depth had a more complex changing pattern. It indicated that the patterns of hyporheic flux were also depthdependent.

\section{CONCLUSIONS}

(a) During the monitoring period, the stream water and air temperatures fluctuated approximately sinusoidally while the amplitude of the former was damped compared with the latter due to the difference in heat capacity. At the same time, the groundwater temperatures showed no significant variation. With the increase of streambed depth, the amplitude of the temperature oscillation was more attenuated and the phase lag was larger.

(b) During the two-day monitoring period, the stream water recharged groundwater and the vertical hyporheic flux ranged from $87 \mathrm{~L} /\left(\mathrm{m}^{2} \cdot \mathrm{d}\right)$ to $306 \mathrm{~L} /\left(\mathrm{m}^{2} \cdot \mathrm{d}\right)$. The hyporheic flux at different depths varied through time and had depth-dependent changing patterns. The hyporheic flux in the shallow zone had more variability and tended to be stable with the increasing of depth. The river stage slightly increased during the period of temperature monitoring; the hyporheic flux was probably affected by the river stage dynamics, but was not solely dependent on it. The groundwater flow distribution and its dynamics probably significantly affected the pattern of hyporheic flux.

Acknowledgements This research was supported by a National Natural Science Foundation of China grant (41201029), China Postdoctoral Science Foundation (2013M540410), and National Undergraduate Training Programs for Innovation (201410294004).

\section{REFERENCES}

Anderson, M. (2005) Heat as a ground water tracer. Ground Water 43, 951-968.

Buffington, J.M., and D. Tonina. (2009) Hyporheic exchange in mountain rivers II: Effects of channel morphology on mechanics, scales, and rates of exchange. Geography Compass 3(3), 1038-1062.

Constantz, J. and Stonestrom, D.A. (2003) Heat as a tracer of water movement near streams. US Geological Survey circular. (1260): 1-96.

Hatch, C.E., et al. (2006) Quantifying surface water-groundwater interactions using time series analysis of streambed thermal records: Method development. Water Resources Research 42(10), W10410, doi:10.1029/2005WR004787

Kerry, J., et al.. (2007) Temporal and spatial variability of groundwater-surface water fluxes: development and application of an analytical method using temperature time series. Journal of Hydrology 336(1), 1-16.

Mamer, E.A. and Lowry, C.S. (2013) Locating and quantifying spatially distributed groundwater/surface water interactions using temperature signals with paired fiber-optic cables. Water Resources Research 49(11), 7670-7680.

Rosenberry, D.O., et al. (2013)Temporal variability of exchange between groundwater and surface water based on highfrequency direct measurements of seepage at the sediment-water interface Water Resources Research 49(5), 2975-2986.

Schmidt, C., Bayer-Raich, M. and Schirmer, M. (2006) Characterization of spatial heterogeneity of groundwater-stream water interactions using multiple depth streambed temperature measurements at the reach scale. Hydrology and Earth System Sciences 10, 849-859.

Suzuki, S. (1960) Percolation measurements based on heat flow through soil with special reference to paddy fields. Journal of Geophysical Research 65(9), 2883-2885.

Wang, W., et al. (2004) Research on the conversion relationships between the river and groundwater in the Yellow River drainage area. Science in China Series E: Technological Sciences 47(1), 25-41.

Young, P.C., et al. (2004) The Captain Toolbox. Centre for Research on Environmental Systems and Statistics. Lancaster University. Available from: www.e-s.lancs.ac.uk/cres/captain.

Zhu, J.S., Shu, L.C. and Lu, C.P. (2013) Study of heterogeneity characteristics of vertical hyporheic flux using a heat tracing method. Journal of Hydraulic Engineering 44(7), 818-825. 